\title{
СОЦИАЛЬНО-ПОЛИТИЧЕСКИЕ И МЕДИЦИНСКИЕ АСПЕКТЫ УПОТРЕБЛЕНИЯ АЛКОГОЛЯ В СТАРШЕM ВОЗРАСТЕ КАК ФАКТОР РИСКА
}

Статья посвящена анализу роли употребления алкоголя в структуре факторов социального неблагополучия в старшем возрасте. Проанализированы социально-политические международные и российские документы, рассматривающие старение. Анализ показывает, при каких условиях быстро растущее население пожилого возраста может оставаться здоровым, что позволяет снизить нагрузку на системы здравоохранения, социального обеспечения и занятости населения. При этом особе внимание уделяется проблеме употребления алкоголя. Затем приводятся данные особенностей жизнеобеспечения 713 лиц пожилого и старческого возраста (от 60 до 89 лет) в Архангельской области. На основании исследования проведена оценка воздействия и последствий употребления алкоголя как выраженного дестабилизирующего механизма на социальные параметры жизни. Трудности адаптации респондентов прямо или косвенно связаны с ограничением деятельности, вызванным снижением или утратой трудоспособности, одиночеством, неадекватными социальными навыками, социальной изоляцией, недостатком физической активности, что нередко приводит к употреблению спиртных напитков, как средству «ухода» от накопившихся проблем. Одиночество, как проявление социальной изолированности, один из наиболее опасных факторов, стимулирующих лиц пожилого и старческого возраста прибегать к «допингу», в роли которого в большинстве случаев выступает алкоголь.

Елена Юрьевна Голубева - д. биол. н., профессор, кафедра социальной работы и социальной безопасности, Высшая школа социально-гуманитарных наук и межкультурной коммуникации Северного (Арктического) федерального университета имени М.В. Ломоносова, Архангельск, Россия. Электронная почта: e.golubeva@narfu.ru

Соловьев Андрей Горгоньевич - д. мед. н., профессор, заведующий кафедрой психиатрии и клинической психологии, Северный государственный медицинский университет Минздрава России, Архангельск, Россия. Электронная почта: ASoloviev1@yandex.ru 
Определена частота употребления спиртных напитков в зависимости от половозрастных характеристик и уровня образования; рассмотрены последствия потребления алкоголя лицами пожилого возраста в качестве факторов риска социального неблагополучия на макро-, микросоциальном и личностном уровнях. Полученные результаты могут быть использованы при актуализации региональных исследований по качеству жизни пожилого населения в регионах с высоким риском потребления алкогольных напитков, а также разработке программ социальной политики с учетом демографического развития и повышения доступности медицинской помощи лицам пожилого возраста.

Ключевые слова: лица пожилого возраста, употребление алкоголя, социальная политика в отношении пожилых, факторы социального риска

DOI: $10.17323 / 727-0634-2018-16-1-67-80$

Согласно данным европейских демографических исследований, доля пожилого населения в Европе увеличится с 17,9\% в настоящее время до 29,3\% к 2060 г. (Eurostat 2014). Старость приносит с собой проблемы, связанные с изменением привычных жизненных стандартов, болезнями, душевными переживаниями, которые целесообразно рассматривать в качестве важных факторов риска социального неблагополучия на макро-, микросоциальном и личностном уровнях. Снижение адаптационных возможностей, а также изменения в социальном положении в совокупности приводят к существенной трансформации физических возможностей и психической деятельности.

На микросоциальном уровне проблемы пожилых обусловлены ослаблением родственных связей и возможностей получения помощи и ухода, неблагоприятной эмоциональной обстановкой в семье, нередкой потерей члена семьи, что, в свою очередь, ведет к снижению социального статуса и нарастанию экономической зависимости. За последние несколько десятилетий на фоне увеличения продолжительности жизни произошла атомизация общества, сократившая роль семьи и создавшая проблему одиночества, приводящего к исключенности из общественной жизни и влияющего на ухудшение самочувствия и здоровья (Елютина, Трофимова 2017). На личностном уровне социальные проблемы обусловлены трудностями поддержания привычного образа жизни и адаптации к меняющимся практикам, чувством незащищенности, приводящими к снижению возможностей, нарушению повседневной деятельности, а также выраженному психосоциальному стрессу, сопровождающемуся различными вариантами саморазрушительного поведения, включая употребление алкоголя.

Принимая во внимание этот контекст, мы ставим перед собой задачу установить роль практик употребления алкоголя лицами пожилого возраста в структуре факторов социальных рисков при старении. Для этого проанализированы два источника данных - основные социально-политические 
международные и российские документы, посвященные старению и анкетный опрос (713 респондентов от 60 до 89 лет) в Архангельской области в рамках специального исследования.

\section{Проблемы употребления алкоголя В геронтологических социально-политических документах}

В Глобальной стратегии и плане действий по старению и здоровью (WHO 2014a) решение проблемы старения населения видится в том, чтобы способствовать здоровому старению и приспособить социальные структуры и политику к включению лиц пожилого и старческого возраста в общество. Злоупотребление алкоголем входит в перечень ведущих факторов риска состояния глобального популяционного здоровья (Jernigan et al. 2000). По оценкам экспертов ВОЗ, в мире от состояний, обусловленных употреблением алкоголя в 2008 г. умерло 2,5 млн чел., а в 2014 г.- уже 3,3 млн. Вклад алкогольной составляющей в общей структуре смертности за тот же период вырос с 4,0\% до 5,9\% (WHO 2014b). В связи со старением населения эксперты ожидают рост числа лиц пожилого возраста, имеющих психические нарушения и проблемы зависимости, прежде всего алкогольного характера (Wu, Blazer 2014). Распространенность злоупотребления алкоголем, включая алкогольную зависимость у лиц старше 65 лет, в разных странах колеблется от 1 до 10\%, приобретая черты «скрытой эпидемии» (Егоров, Шайдукова 2005).

В основных социально-политических документах в отношении лиц пожилого возраста, таких как Мадридский план действий по проблемам старения (WHO 2014c), отмечается важность уменьшения совокупного воздействия факторов, повышающих риск алкогольной зависимости в пожилом возрасте, и принятия комплексных мер, направленных на предупреждение злоупотребления алкоголем. Концепция активного старения BO3 (WHO 2002) основана на трех составляющих, упомянутых в определении активного долголетия: участие, здоровье и безопасность. Предлагаемая модель имеет шесть групп детерминант, в т. ч. поведенческие курение, физическая активность, потребление пищи, здоровье полости рта, алкоголизация (Paul et al. 2012). В документе отмечено:

В то время как пожилые люди склонны пить меньше, чем молодые, изменения обмена веществ, которые сопровождают старение, повышают их восприимчивость к заболеваниям, связанным с алкоголем, включая заболевания печени, желудка и поджелудочной железы. Пожилые люди имеют больший риск для ассоциированных с алкоголем падений и травм, а также потенциальных опасностей, связанных со смешиванием алкоголя и медикаментов (WHO 2002).

Национальный документ «Стратегия действий в интересах граждан старшего поколения в Российской Федерации до 2025 года» (Правительство РФ 
2016) показывает меры по уменьшению факторов риска, связанные с занятостью пожилого населения, развитием различных форм активности, улучшением доступности и качества медицинской помощи, что косвенно может указывать на пути решения проблем, связанных с алкоголизацией лиц пожилого возраста, особенно вышедших на пенсию.

\section{Роль употребления алкоголя В структуре факторов риска при старении}

В оценке эффектов злоупотребления алкоголем на общественном уровне рассматриваются четыре основных компонента - медицинский, социальный, демографический и экономический (Соловьев и др. 2016). При этом первые два в большей степени отражают растущие проблемы у лиц пожилого возраста в контексте алкоголизации.

Наличие алкогольной зависимости в старости характеризуется исследователями алкоголизма как «жизненный отпечаток», имевший место в течение многих лет («ранний дебют»), или как ответная реакция на возрастные стрессы («поздний дебют»). Если в первом случае злоупотребление алкоголем - явление, которое уже существовало, но не было выявлено до настоящего момента, то во втором - оно обусловлено индивидуальными и, главным образом, социальными аспектами старения. Не вдаваясь в клинические особенности течения алкогольной зависимости в пожилом возрасте, можно отметить, что нарастающее соматическое неблагополучие препятствует интенсивной алкоголизации в случае относительно сохранной критической способности индивида (Надеждин 2016). В то же время растущая цереброваскулярная недостаточность в сочетании с токсическим действием алкоголя и алиментарной недостаточностью может приводить к противоположным эффектам - быстрому нарастанию алкоголь-атрибутивных проблем, все более отчетливо проявляющихся и на социальном уровне.

Наше исследование особенностей жизнеобеспечения касается 713 лиц пожилого и старческого возраста от 60 до 89 лет, из которых 23 \% составляли мужчины, 77\% - женщины, при этом 24,5\% принадлежали к городской, 75,5\% - к сельской популяции Архангельской области. Согласно критериям ВО3, обследованные были распределены нами на три возрастные группы: 60-69 лет - 55,2\%, 70-79 лет - 35,1\% и 80-89 лет - 9,7\% (Голубева 2016).

Для оценки жизнеобеспечения и факторов риска социального благополучия лиц пожилого и старческого возраста использовался метод интервью с применением опросника BO3 ELSA (Jylha et al. 1992), включающего 125 вопросов закрытого типа, рекомендованных для европейских лонгитюдных исследований старения. Опросник содержит следующие блоки: социальный статус, состояние здоровья, удовлетворенность жизнью, условия проживания, материальное положение, социокультурные потребности, употребление спиртных напитков и др. Статистический анализ данных 
проводился с помощью программного пакета SPSS 15.0 и Excel 2000. Использовались параметрические и непараметрические методы. Дисперсионный анализ интерпретировался лишь при однородности дисперсий. Взаимосвязи различных переменных изучались с помощью корреляционного анализа с определением коэффициента корреляции Пирсона. Анализ номинальных и порядковых шкал осуществлялся с помощью критерия $\chi 2$ Пирсона. Статистически значимыми считали различия, при которых показатель уровня статистической значимости (p) был ниже 0,05 .

Длительное употребление алкоголя значительно изменяет оценку уровня благополучия и общей удовлетворенностью жизнью - важных составляющих параметров качества жизни, как степени удовлетворения человека физическим и психическим состоянием, а также социальным функционированием (Гузова и др. 2010). Оценка воздействия и последствий алкоголизации, как выраженного дестабилизирующего механизма на социальные параметры жизни популяции лиц пожилого возраста в Архангельской области, проведенная нами на основании факторного анализа, показала следующие результаты (рис. 1).

Как часто вы употребляете алкогольные напитки? \%

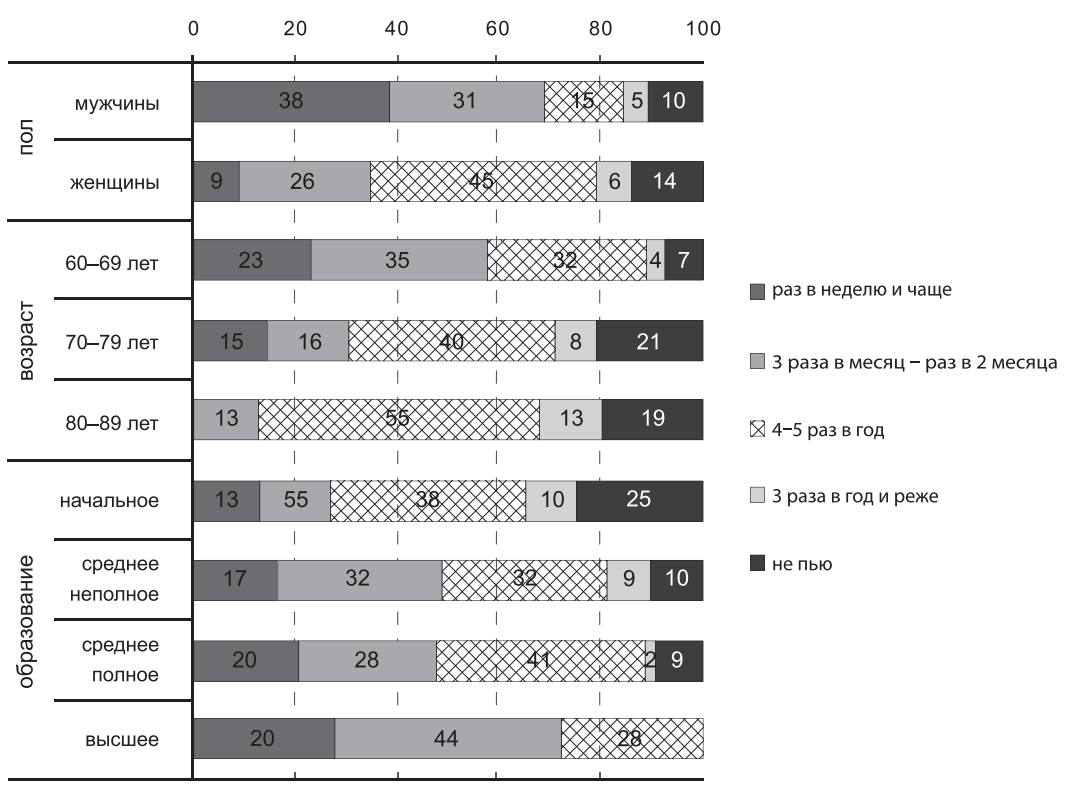

Puc. 1. Частота употребления спиртных напитков лицами пожилого возраста в зависимости от половозрастных характеристик и уровня образования, (\%).

Фактор пола был представлен на первом месте ( $\mathrm{F}=39,801, \mathrm{p}<0,01)$. Частота употребления алкоголя у 38 \% мужчин составляла до нескольких 
раз в неделю, что позволяет делать вывод о высокой степени употребления алкоголя пожилыми мужчинами, особенно в возрастной группе 60-69 лет. При этом у лиц с высшим образованием, вышедших на пенсию, данная тенденция является наиболее выраженной.

Употребление спиртных напитков с высокой крепостью (более $40^{0}$ ) оказалось тесно связано с полом $(\mathrm{F}=33,32, \mathrm{p}<0,01)$ : значительно сильнее данная связь представлена у мужчин; остальные факторы имели меньшее значение, хотя, как и в предыдущем случае, обращает на себя внимание, что $41 \%$ респондентов в группе 60-69 лет, предпочитающих крепкий алкоголь, также имели высшее образование (рис. 2). Употребление вина достаточно распространено среди пожилых мужчин и женщин (45\% и 35 \%, соответственно) во всех возрастных группах с преобладанием более «молодой» - 60-69 летней группы. Дисперсионный анализ демонстрирует преобладание фактора «образование» $(\mathrm{F}=4,636)$. Потребление слабоалкогольных напитков - в основном пива - превалировало в выборке мужчин 60-69 лет $(\mathrm{F}=37,841, \mathrm{p}<0,01)$ и мало встречалось у пожилых женщин, не превышая 6\%. Более высокие значения показателей зарегистрированы у лиц с неполным средним образованием среди 60-69 летних.

\section{Употребляете ли вы крепкие напитки? \%}

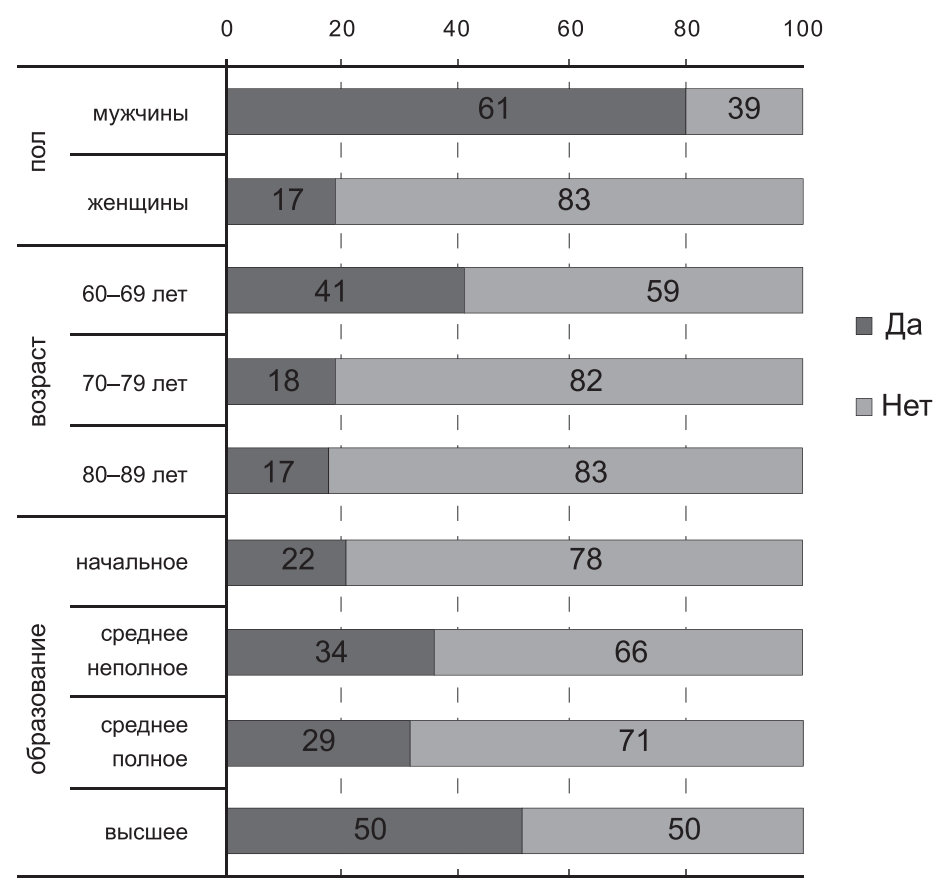

Puc. 2. Доля потребляемых крепких спиртных напитков лицами пожилого возраста в зависимости от поло-возрастных характеристик и уровня образования, \%. 
Трудности адаптации респондентов связываются нами с ограничением деятельности, вызванным снижением или утратой трудоспособности, одиночеством, неадекватными социальными навыками, социальной изоляцией, недостатком физической активности, что является проявлениями экстремальной социальной ситуации и нередко приводит к употреблению спиртных напитков, как средству «ухода» от накопившихся проблем. Фактор, связанный с проблемами ухудшения состояния здоровья за последние 10 лет, выявлен во всех возрастных группах.

Несомненно, в силу обстоятельств (болезни, смерти друзей, переезда на новое место жительства) у лиц старшей когорты сужается круг общения. Разрыв связей или их полное отсутствие могут вызвать или обострить чувство одиночества, обделенности, ненужности, оторванности от окружающего мира. Фактор одиночества связан как с неблагополучными семейными отношениями, так и с потерей супруга, друзей или отсутствием семьи. Одиночество, нередко тождественное социальной изолированности,- один из наиболее опасных феноменов, стимулирующих лиц пожилого и старческого возраста прибегать к употреблению алкоголя, что провоцирует неблагоприятные социальные последствия и является фактором, ассоциированным с преждевременной смертью, особенно в северных регионах страны (Соловьев и др. 2014).

Семейная взаимопомощь позволяет сгладить последствия одиночества, экономических трудностей, преодолеть негативные изменения социального статуса после выхода на пенсию. Уход, осуществляемый родственниками, стимулирует умственную деятельность лиц пожилого и старческого возраста, убеждает их в собственной полезности и усиливает желание жить, способствуя безопасности на микроуровне. Семья обеспечивает пожилому индивиду ежедневный уход, лечение, сопровождение, помощь в ведении домашнего хозяйства, выступает посредником между лицами пожилого и старческого возраста и местной системой здравоохранения и социального обслуживания. Включенность лиц старшей возрастной группы в выполнение хозяйственно-бытовой и воспитательной функции сопровождается осознанием своей полезности, положительно влияет на процессы социализации и социальной адаптации (Голубева 2014).

Вдовство нередко представляется концом семейного жизненного цикла, вызывая серьезные депрессивные реакции, приводящие к злоупотреблению алкоголем. Чувство одиночества больше тревожит женщин, не состоявших в браке или разведенных, чем мужчин (Гузова и др. 2010) и сильнее проявляется с возрастом. Злоупотребление алкоголем женщин позднего возраста рассматривается некоторыми исследователями в связи с нарушением социально-психологического и семейного статусов (Кривулин и др. 2014). Тягостное переживание смерти супруга/супруги нередко становится причиной нарушения психического состояния. Депрессия, тревога и симптомы «осложненного горя» числятся среди наиболее важных психиатрических 
осложнений при подобных обстоятельствах. Осложнения могут представлять собой, в частности, формы патологических реакций на стресс, вызванный переживаниями тяжелой утраты, и необходимость адаптации к новым условиям. Кроме того, алкоголь в пожилом возрасте может употребляться как «лекарство» от бессонницы в качестве снотворного или успокаивающего средства. Так как лица пожилого и старческого возраста в среднем имеют по три-четыре хронических заболевания, которые могут сопровождаться болезненными ощущениями, алкогольные напитки используются ими в качестве болеутоляющего средства (Osgood, Manetta 2002). В то же время нужно помнить и об усилении возможного неблагоприятного влияния на организм пожилых людей и роста побочных реакций при совместном употреблении лекарственных препаратов и алкоголя (Ilomki et al. 2013).

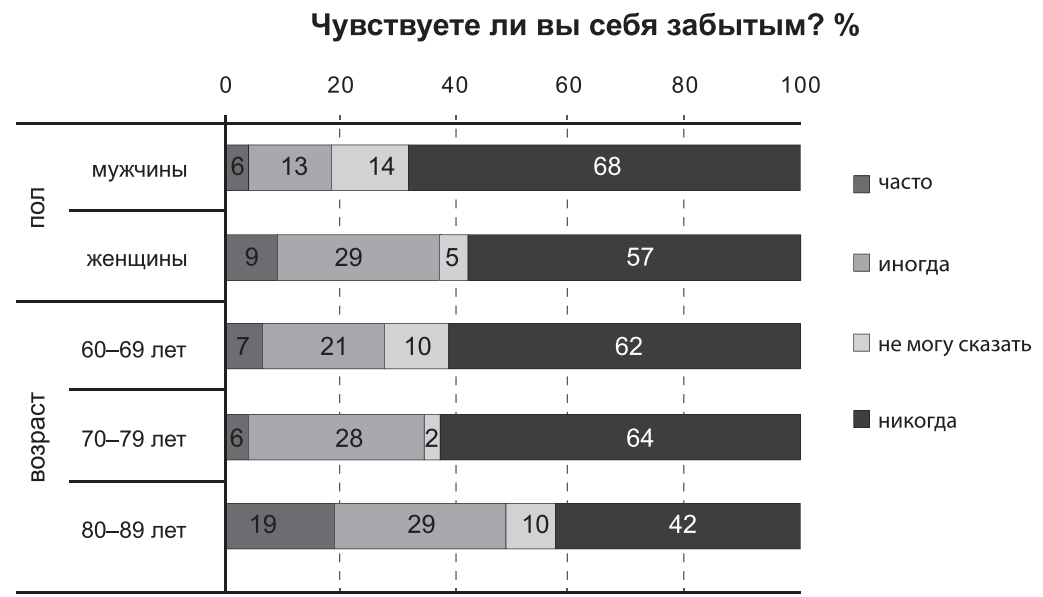

Puc. 3. Частота встречаемости чувства забытости лицами пожилого и старческого возраста в зависимости от половозрастных характеристик и уровня образования, (\%).

Значимым социальным показателем, отражающим адаптационные возможности лиц пожилого и старческого возраста, является их трудовая занятость. Один из самых глубоких психосоциальных кризисов личности связан с выходом на пенсию, что отражается на последующей адаптации человека к своему положению. Для респондентов существенным являлось резкое изменение структуры занятости. Кроме того, выход на пенсию представлялся «потерей будущего», и жизненный мир понимался неопределенным и бессодержательным без работы. Потеря социальной роли «кормильца», ощущения своей полезности на работе, увеличение экономической зависимости за счет получения дохода только в виде пенсии обостряют чувства ненужности в пожилом и старческом возрасте (рис. 3). В выборке это более всего проявлялось в зависимости от двух факторов - 
пола $(\mathrm{F}=6,801, \mathrm{p}<0,05)$ и образования $(\mathrm{F}=4,574, \mathrm{p}<0,05)$. У женщин 80-89 лет чувство ненужности было выражено сильнее, такая же тенденция выявлена и у лиц с начальным и средним образованием.

Корреляционный анализ по методу Пирсона показал, что респонденты, занимавшиеся интеллектуальным трудом, оценивали свое здоровье на данный момент лучше, реже употребляли спиртные напитки, выше оценивали свое материальное благосостояние и больше времени уделяли различным физическим нагрузкам (например, прогулкам).

Таким образом, результаты исследования показывают, что возрастная группа 60-69 лет может рассматриваться в качестве группы риска по развитию алкогольной зависимости, причем в гендерном отношении превалируют мужчины. Наиболее важными причинами, способствующими алкоголизации, являются выход на пенсию и адаптация к новым социальным условиям, а также изменение психического состояния с нарастанием раздражительности и депрессии. На микросоциальном уровне отчетливо прослеживается взаимосвязь употребления алкоголя с социально-психологическими нарушениями, при этом отсутствие/нарушение семейной поддержки может провоцировать алкоголизацию лиц пожилого возраста в качестве средства «ухода от действительности». Ситуация осложняется тем, что представители старшей возрастной группы нередко испытывают чувство беспокойства за свое будущее и будущее своей семьи, для «притупления» которого и необходим алкоголь.

На индивидуальном уровне употребление алкоголя может восприниматься пожилыми как последнее доступное удовольствие; в данном случае они менее мотивированы на изменение стиля жизни и поведения по укреплению здоровья, так как воспринимают свои физические ограничения как неизбежный компонент старения.

\section{Заключение}

Социально-политические документы демонстрируют проблемные точки социальной политики и ее инструментов в ситуации, когда быстрорастущее население пожилого и старческого возраста рискует здоровьем. Сохранение здоровья в этом возрасте позволит снизить нагрузку на системы здравоохранения, социального обеспечения и занятости населения. При этом следует уделить внимание проблеме употребления алкоголя в пожилом возрасте. Однако сформулированные международными институтами рекомендации практически не находят применения в России: в принятой национальной Стратегии (Правительство РФ 2016) на фактор риска, связанный с алкоголем, внимания не обращается, проводится недостаточно исследований в этом направлении.

В литературных источниках выявляются факторы социально-психологического характера, влияющие на снижение активности людей пожилого 
и старческого возраста: изменение жизненной ситуации, в том числе прекращение систематической трудовой и общественной деятельности (Григорьева и др. 2015), резкая смена обстановки (Краснова 2014), сужение объема обязанностей (Максимова и др. 2016), одиночество, усталость, тревога (Елютина, Трофимова 2017). Все это провоцирует употребление алкоголя в качестве средства «ухода от действительности», что было подтверждено результатами проведенного исследования (ср., Надеждин 2016).

В этой ситуации акцент на уровне общественного здоровья должен быть сделан на активном внедрении первичной и вторичной профилактики алкогольной зависимости среди представителей старшей возрастной группы. Международная практика показывает, что развитие страны, особенно северной, лучше протекает при ограничительной алкогольной политике (Кошкина, Павловская 2012). В то же время продолжение запретительноограничительной кампании не изменило существенным образом ситуацию в направлении снижения объемов потребления алкоголя. Однако актуализация алкогольной проблематики создает предпосылки более жесткого отношения общества и государственных органов к чрезмерному потреблению алкоголя. Эффективными могут оказаться региональные программы и меры по повышению доступности медицинской помощи пожилым, групповых и индивидуальных маршрутов первичной и вторичной профилактической антинаркотической работы, сохранению семейных отношений и предотвращению социальной изолированности пожилых.

\section{Список источников}

Голубева Е.Ю (2014) Роль социально-медицинского обслуживания в повышении качества жизни пожилого населения в российской части Баренц-Евроарктического региона. Успехи геронтологии, 27 (2): 310-314.

Голубева Е.Ю (2016) Системный анализ факторов, влияющих на качество жизни пожилого населения при использовании разных форм социального обслуживания. Успехи геронтологии, 29 (2): 347-352.

Григорьева И.А., Видясова Л.А., Дмитриева А.В., Сергеева О.В (ред.) (2015) Пожилье в современной России: между занятостью, образованием и здоровьем. СПб.: Алетейя. Гузова А. В., Голубева Е. Ю., Соловьев А. Г. (2010) Особенности качества жизни и биологического возраста пожилых лиц с алкогольной зависимостью в условиях Европейского Севера. Успехи геронтологии, 23 (1): 58-61.

Егоров А. Ю., Шайдукова Л.К. (2005) Современные особенности алкоголизма у женщин: возрастной аспект. Наркология, (9): 49-55.

Елютина М.Э., Трофимова О.А. (2017) Одинокое проживание и переживание одиночества в позднем возрасте. Журнал исследований социальной политики, 15 (1): 37-50.

Кошкина Е.А., Павловская Н.И. (2012) Анализ алкогольной политики в странах партнерства «Северное измерение» и рекомендации по повышению ее эффективности. Вопросы наркологии, (5): 62-67.

Краснова О.В. (2014) Выход на пенсию и идентичность женщин. Психологические исследования, 7 (35): 6. 
Кривулин Е.Н.. Мингазов А. Х., Власов А. А., Юркина Н. В. (2014) Возрастные клинико-динамические особенности алкоголизма раннего и позднего возраста. Всероссийская междисииплинарная научно-практической конференция «Актуальные проблемы возрастной наркологии и профилактики аддиктивных состояний». Челябинск: 26-30.

Максимова С.Г., Ноянзина О. Е., Максимова М. М. (2016) Социальная политика в отношении старших возрастных групп как основа преодоления социальной эксклюзии: экспертные оценки. Вестник Алтайского государственного аграрного университета, 6 (140): 177-182.

Надеждин А. В. (2016) Влияние возрастного фактора на клинику наркологических заболеваний. Наркология, (5): 90-99.

Правительство РФ (2009) Конщепция государственной политики по снижению масштабов злоупотребления алкоголем и профилактике алкоголизма среди населения Российской Федерации на период до 2020 года № 2128-р от 30.12.2009 г.

Правительство РФ (2016) Распоряжение об утверждении Стратегии действий в интересах граждан старшего поколения в Российской Федераџии до 2025 года № 164-р от 05.02.2016 г.

Соловьев А. Г., Мордовский Э. А., Вязьмин А. М. (2014) Социально-демографический статус лиц пожилого и старческого возрастов, умерших от алкоголь-атрибутивных состояний в г. Архангельске. Успехи геронтологии, (1): 165-171.

Соловьев А. Г., Мордовский Э. А., Санников А. Л. (2016) Количественная оценка совокупного ущерба от злоупотребления алкоголем на популяционном уровне. Наркология, (1): 16-32.

Eurostat (2014) Eurostat Regional Yearbook. Available at: http://ec.europa.eu/eurostat/documents/3217494/5786129/KS-HA-14-001-00-EN.PDF (accessed 15 October 2016).

Ilomki J., Paljarvi T., Korhonen M., Enlund H., Alderman C., Kauhanen J., Bell J. (2013) Prevalence of Concomitant Use of Alcohol and Sedative Hypnotic Drugs in Middle and Older Aged Persons: A Systematic Review. Annual Pharmacother, (2): 257-268.

Jernigan D. H., Monteiro M., Room R., Saxena S. (2000) Toward a Global Alcohol Policy: Alcohol, Public Health and the Role of WHO. Bulletin of the World Health Organization, 78 (4): 491-499.

Jylha M., Jokela J., Tolvanen E., Heikkinen E. (1992) The Tampere Longitudinal Study on Ageing. Scandinavian Journal of Social Medicine, (47): 58-76.

Osgood N. J., Manetta A.A. (2002) Physical and Sexual Abuse, Battering, and Substance Abuse: Three Clinical Cases of Older Women. Journal of Gerontological Social Work, 38 (3): 45-61.

Paul C., Ribeiro O., Teixeira L. (2012) Active Ageing: An Empirical Approach to the WHO Model. Current Gerontology and Geriatrics Research. Available at: http://dx.doi. org/10.1155/2012/382972 (accessed 15 September 2016).

WHO (2002) Active Ageing: A Policy Framework. Available at: http://www.who.int/ageing/publications/active_ageing/en/ (accessed 12 October 2013).

WHO (2014a) Global Strategy and Action Plan on Ageing and Health. Available at: http:// www.who.int/ageing/global-strategy/en/ (accessed 01 July 2017).

WHO (2014b) Global Status Report on Alcohol and Health. Geneva: Department of Mental Health and Substance Abuse.

WHO (2014c) Madrid International Plan of Action on Aging. Available at: www.who.int/ ageing/events/mipaa/en (accessed 11 September 2014).

Wu Li-Tzy, Blazer D. G. (2014) Substance Use Disorders and Psychiatric Comorbidity in Mid and Later Life: A Review. International Journal of Epidemiology, (2): 302-317. 
Elena Golubeva, Andrey Soloviev

\section{THE SOCIO-POLITICAL AND MEDICAL ASPECTS OF ALCOHOL ABUSE AS A FACTOR OF RISK CAUSING SOCIAL DISTRESS AMONG OLDER AGE GROUPS}

The article analyses the role of alcohol consumption as a risk factor increasing social disadvantage among older age groups. Firstly, the problem of alcohol abuse among the elderly is considered with reference to the major sociopolitical international and Russian documents. These documents outline the key elements of state policies and the instruments in use, which aim to keep a rapidly growing elderly population healthy, thus reducing the burden on the health system and social security and employment. Particular attention is paid here to the problem of alcoholism among the elderly. Based on the results of empirical studies of the lifestyles of 713 of people aged 60 to 89 in the Arkhangelsk region, this paper offers an evaluation of the impact and consequences of alcoholism, which can be viewed as a destabilizing mechanism in social life settings. The main difficulties in that respondents highlighted that, directly or indirectly, led to alcohol use were the limitation of activities caused by the reduction or disability, loneliness, inadequate social skills, social isolation, lack of physical activity. Thus, consumption of alcohol can be understood as a 'withdrawal' from one's accumulated problems. Loneliness as a manifestation of social exclusion is one of the most dangerous stimulants towards alcohol use among the elderly, which can be seen as a form of 'doping'. The frequency with which alcoholic beverages are consumed depends on gender and age characteristics, as well as education level. Another important factor to be considered is the consequences of the alcohol consumption of older persons as an important risk factor for social disadvantage at the macro-, micro-social and personal levels. The results obtained here update regional studies on the life quality of the elderly population in the regions, revealing a high risk of alcoholic consumption, as well as the development of social policies due to the demographic development and the increase in the availability of medical care for the elderly.

Key words: older age, alcoholism, social policy towards older people, risk factors of social disadvantage of aging

DOI: $10.17323 / 727-0634-2018-16-1-67-80$

\footnotetext{
Elena Golubeva - PhD, Professor of the Department of Social Work and Social Security, Higher School of Social Sciences, Humanities and International Communication, Northern (Arctic) Federal University named after M.V. Lomonosov, Arkhangelsk, Russian Federation. Email: e.golubeva@narfu.ru
}

Andrey Soloviev - MD, PhD, Professor of Psychiatry, Chief, Department of Psychiatry and Clinical Psychology, Northern State Medical University, Arkhangelsk, Russian Federation. Email: ASoloviev1@yandex.ru 


\section{References}

Egorov A., Shaydukova L. (2005) Sovremennyye osobennosti alkogolizma u zhenshchin: vozrastnoy aspekt [Modern Features of Women's Alcoholism: The Age Aspect]. Narkologiya [Narcology], (9): 49-55.

Elyutina M., Trofimova O. (2017) Odinokoye prozhivaniye i perezhivaniye odinochestva v pozdnem vozraste [Lonely Living and Experiencing Loneliness in Later Life]. Zhurnal Issledovaniy Sotsial'noy Politiki [The Journal of Social Policy Studies], 15 (1): 37-50.

Eurostat (2014) Eurostat Regional Yearbook. Available at: http://ec.europa.eu/eurostat/documents/3217494/5786129/KS-HA-14-001-00-EN.PDF (accessed 15 October 2016).

Golubeva E. Y. (2016) Sistemnyy analiz faktorov, vliyayushchikh na kachestvo zhizni pozhilogo naseleniya pri ispol'zovanii raznykh form sotsial'nogo obsluzhivaniya [System Analysis of Factors Affecting the Quality of Life of Aged People in Their Use of Different Forms of Social Services]. Uspekhi gerontologii [Advances in Gerontology], 29 (2):347-352.

Grigor'yeva I.A., Vidyasova L. A., Dmitriyeva A. V., Sergeyeva O. V. (eds.) (2015) Pozhilyye v sovremennoy Rossii: mezhdu zanyatost'yu, obrazovaniyem i zdorov'yem [Elderly People in Modern Russia: Between Occupation, Education and Health]. St. Petersburg: Aleteyya.

Guzova A., Golubeva E., Soloviev A. (2010) Osobennosti kachestva zhizni i biologicheskogo vozrasta pozhilykh lits s alkogol'noy zavisimost'yu v usloviyakh Evropeyskogo Severa [Features of the Quality of Life and Biological Aging of Alcohol Dependency among Older People]. Uspekhi gerontologii [Advances in Gerontology], 23 (1): 58-61.

Ilomki J., Paljarvi T., Korhonen M., Enlund H., Alderman C., Kauhanen J., Bell J. (2013) Prevalence of Concomitant Use of Alcohol and Sedative Hypnotic Drugs in Middle and Older Aged Persons: A Systematic Review. Annual Pharmacother, (2): 257-268.

Jernigan D., Monteiro M., Room R., Saxena S. (2000) Toward a Global Alcohol Policy: Alcohol, Public Health and the Role of WHO. Bulletin of the World Health Organization, 78 (4): 491-499.

Jylha M., Jokela J., Tolvanen E., Heikkinen E. (1992) The Tampere Longitudinal Study on Ageing. Scandinavian Journal of Social Medicine, (47): 58-76.

Koshkina Ye.A., Pavlovskaya N.I. (2012) Analiz alkogol'noy politiki v stranakh partnerstva 'Severnoye izmereniye' i rekomendatsii po povysheniyu yeye effektivnosti [Analysis of the Alcohol Policy in the Northern Dimension Partnership Countries and Recommendations for Improving its Effectiveness]. Voprosy narkologii [Narcological issues], (5):62-67.

Krasnova O. V. (2014) Vykhod na pensiyu i identichnost' zhenshchin [Retirement and Identity of Women]. Psikhologicheskiye issledovaniya [Psychological Research], 7 (35): 6.

Krivulin Ye.N.. Mingazov A.KH., Vlasov A.A., Yurkina N. V. (2014) Vozrastnyye klinikodinamicheskiye osobennosti alkogolizma rannego i pozdnego vozrasta [Age Clinico-Dynamic Features of Alcoholism of Early and Late Age]. Vserossiyskaya mezhdistsiplinarnaya nauchno-prakticheskaya konferentsyia 'Aktual'nyye problemy vozrastnoy narkologii i profilaktiki addiktivnykh sostoyaniy' [All-Russian International Academic and Practical Conference 'Current Issues of Ageing, Narcology and Prevention of Addictive Behaviour']. Chelyabinsk: 26-30.

Maksimova S. G., Noyanzina O. Ye., Maksimova M.M. (2016) Cotsial'naya politika v otnoshenii starshikh vozrastnykh grupp kak osnova preodoleniya sotsial'noy eksklyuzii: ekspertnyye otsenki [Social Policy for Older Age Groups as a Basis for Overcoming Social Exclusion: Expert Assessments]. Vestnik Altayskogo gosudarstvennogo agrarnogo universiteta [Altai State Agrarian University Review], 6 (140): 177-182. 
Nadezhdin A. V. (2016) Vliyaniye vozrastnogo faktora na kliniku narkologicheskikh zabolevaniy [Age Factor Influence on the Clinic of Narcological Diseases]. Narkologiya [Narcology], (5): 90-99.

Osgood N. J, Manetta A. A. (2002) Physical and Sexual abuse, Battering, and Substance Abuse: Three Clinical Cases of Older Women. Journal of Gerontological Social Work, 38 (3): 45-61.

Paul C., Ribeiro O., Teixeira L. (2012) Active Ageing: An Empirical Approach to the WHO Model. Current Gerontology and Geriatrics Research. Available at: http://dx.doi. org/10.1155/2012/382972 (accessed 15 September 2016).

Pravitel'stvo Rossiyskoy Fedratsii (2009) Koncepciya gosudarstvennoj politiki po snizheniyu masshtabov zloupotrebleniya alkogolem i profilaktike alkogolizma sredi naseleniya Rossijskoj Federacii na period do 2020 goda [Order of the Government of the Russian Federation 'The Concept of State Policy to Reduce Alcohol Abuse and Prevent Alcoholism among the Population of the Russian Federation for the Period till 2020'] No.2128-r from 30.12.2009.

Pravitelstvo Rossiyskoy Fedratsii (2016) Ob utverzhdenii Strategii deystviy v interesakh grazhdan starshego pokoleniya $v$ Rossiyskoy Federatsii do 2025 goda [Order of the Government of the Russian Federation 'On the Approval of the Strategy of Action for the Benefit of Citizens of the Older Generation in the Russian Federation until 2025'] No. 164-r from 05.02.2016.

Solov'ev A.G., Mordovskij E.A., Vyaz'min A.M. (2014) Social'no-demograficheskij status lic pozhilogo i starcheskogo vozrastov, umershih ot alkogol'-atributivnyh sostoyanij v g. Arhangel'ske [Socio-demographic Status of Elderly and Senile age People Died from Alcohol-Attributable States in Arkhangelsk]. Uspekhi gerontologii [Advances in Gerontology], (1): 165-171.

Solov'ev A. G., Mordovskij E. A., Sannikov A. L. (2016) Kolichestvennaya ocenka sovokupnogo ushcherba ot zloupotrebleniya alkogolem na populyacionnom urovne. Narkologiya [Narkologia], (1): 16-32.

WHO (2002) Active Ageing: A Policy Framework. Available at: http://www.who.int/ageing/publications/active_ageing/en/ (accessed 12 October 2013).

WHO (2014a) Global Strategy and Action Plan on Ageing and Health. Available at: http:// www.who.int/ageing/global-strategy/en/ (accessed 01 July 2017).

WHO (2014b) Global Status Report on Alcohol and Health. Geneva: Department of Mental Health and Substance Abuse.

WHO (2014c) Madrid International Plan of Action on Aging. Available at: www.who.int/ ageing/events/mipaa/en (accessed 11 September 2014).

Wu Li-Tzy, Blazer D. G. (2014) Substance Use Disorders and Psychiatric Comorbidity in mid and later Life: A Review. International Journal of Epidemiology, (2):302-317. 